\title{
Mitigating the effects of a road on amphibian migrations: a Scottish case study of road tunnels
}

\author{
I.D.C. Hill ${ }^{1}$, C.A. Rossi ${ }^{1}$, S.O. Petrovan ${ }^{2,3}$, M. Hartup ${ }^{2}$, F. Clark² \& J.R. Downie ${ }^{1}$ \\ ${ }^{1}$ Institute of Biodiversity, Animal Health and Comparative Medicine, University of Glasgow, Glasgow G12 8QQ \\ 2 Froglife, 1 Loxley, Werrington, Peterborough PE4 5BW \\ ${ }^{3}$ Conservation Science Group, Department of Zoology, The David Attenborough Building, University of \\ Cambridge, Cambridge CB3 3QZ
}

E-mail: roger.downie@glasgow.ac.uk

\begin{abstract}
The ever-growing pace of road construction worldwide has become a serious concern for wildlife and natural habitats, resulting in habitat fragmentation and increasing wildlife road fatalities. For amphibians, which are undergoing population declines worldwide, mitigation measures such as road under-passages linked to amphibian-proof fencing may be an effective conservation tool, aiming to reconnect natural habitats and reduce wildlife fatalities. This study assessed the efficacy of road tunnels in a recently developed area by Frankfield Loch, Stepps, North Lanarkshire. Three amphibian tunnels, plus fencing, were put in place during 2010 following the construction of a road in 2006 which separated the loch from a substantial area of marshland, including ponds. In 2015 and 2016, we used custom-made time-lapse cameras within the tunnels to automatically monitor amphibian movements and conducted frog spawn surveys. Numbers of common frogs (Rana temporaria), common toads (Bufo bufo) and newts (Lissotriton spp.) using the tunnels were substantial in both years, though the number of toads decreased significantly between years. We found many frog spawn clumps in the marsh ponds, but rather fewer in the loch. A period of road repair in 2015 was linked with both road mortalities and a change in the pattern of tunnel usage. Additionally, amphibians showed a daily cycle of activity, with nocturnal movements most common. These results indicate important connectivity and usage of both the marsh and the loch, and suggest that this can be effectively sustained through the proper maintenance of tunnels and fencing, which also minimises road mortalities. It remains unknown, however, what proportion of the population crosses the road via the tunnels and how that compares with movements prior to road construction.
\end{abstract}

\section{INTRODUCTION}

Global amphibian declines are increasingly recognised (Nystrom et al., 2007), with over 30\% of species listed as threatened including $8.1 \%$ critically endangered (IUCN, 2015). These declines have been attributed, in part, to climate change (Kiesecker et al., 2001), pathogens (Pounds et al., 2006), and direct impact of pollution and habitat fragmentation through urbanisation (Foley et al., 2005). The mobile nature of amphibian species, combined with the majority requiring both aquatic and terrestrial habitats (Richter et al., 2001), and associated breeding site fidelity (Santos et al., 2007), make them particularly vulnerable to anthropogenic disruption. This has led to a need to better understand the mechanisms underpinning amphibian declines (Beebee \& Griffiths, 2005), and to limit negative impacts through a variety of mitigation measures (Petranka et al., 2007).

The anthropogenic influences that lead to habitat fragmentation, particularly the increasing number of roads constructed to connect developed areas, result in the isolation of wildlife habitats pocketed between such areas (Cushman, 2006). Great Britain had a combined road length of $395.7 \mathrm{~K} \mathrm{~km}$ in 2015, an increase of 9.3K km since 1995 (GOV.UK, 2016). Additionally, with over 64 million kilometres of roads recorded worldwide (Van der Ree et al., 2015), it is not surprising that road systems often cut directly across wildlife migration routes and can result in significant wildlife mortality (Roos et al., 2012), with amphibians particularly susceptible (Gryz \& Krauze, 2008). In response to these problems, a wide range of mitigation measures has been employed to prevent animal road deaths, such as warning signs, fences and assisted frog crossings (Al-ghamdi \& Algadhi, 2004; Van der Ree et al., 2015). Fencing along motorways and other roads can reduce wildlife-vehicle collisions and is often used to keep large mammals off the roads, but is ineffective if not managed properly and can also make population fragmentation worse (Jaeger \& Fahrig, 2004). An increasingly utilised solution is the provision of wildlife passages, allowing animals to cross roads without encountering traffic, which have been successfully applied to mammals (Sawaya et al., 2014) and amphibians in the form of road crossing 
tunnels combined with amphibian-proof fences to channel animals towards the tunnel openings (Hamer et al., 2015; Matos et al., 2017). However, varying degrees of successful implementation indicate that the specifications of such mitigations often depend on the species and tunnel design and that more data are required in order to assess their short and long-term effects (Beebee, 2013; Smith et al., 2018).

Frankfield Loch lies on the north-east edge of Glasgow and is one of many "kettle ponds" that were formed in Scotland by glacial retreat after the last Ice Age. It is a component of the Seven Lochs Wetland Park being developed on $16 \mathrm{~km}^{2}$ of terrestrial and freshwater habitat between Glasgow and Coatbridge (www.sevenlochs.org). Woodland and reed beds extend around most of the circumference of the loch, with a large area of marshland and woodland patches to the northeast. This makes the site excellent wildlife habitat, supporting a wide range of species, including four species of amphibian: common frog, common toad, smooth newt (Lissotriton vulgaris) and palmate newt ( $L$. helveticus). These species and their migration paths were identified in preliminary surveys, carried out in 2002 and 2006 (Heritage Environmental, 2006). A housing development has been constructed to the south east of the site and a road was built (2006) connecting the houses to Cumbernauld Road in the north, separating the loch from the marsh and cutting through the likely migration paths of the four amphibian species.

In response to concerns for the wildlife on the site, four road crossing tunnels, three primarily for amphibians and one for water voles (Arvicola amphibius), were built under the road and combined with the installation of barrier fencing, to assist any amphibians and other small animals migrating between the loch and marsh. However, no monitoring of the site or the tunnels had taken place since their installation in 2010. Once housing development has been completed, it is planned that the loch and the undeveloped land will be passed over to North Lanarkshire Council Greenspace Development Services and designated as a Local Nature Reserve.

This study used cameras installed in the amphibian tunnels in 2015 and 2016 to collect data on the animals using the tunnels, with an aim to clarify factors that affect amphibian movements between the marsh and loch sides of the road. The application of modern automatic monitoring techniques allowed for the continuous recording of wildlife activity in the tunnels, without the presence of human beings who could act as a predation risk stimulus (Frid \& Dill, 2002). We aimed to assess: 1) the effectiveness of the tunnels and fences in reducing amphibian road mortalities; 2) the overall patterns of usage of the tunnels during the amphibian breeding season; 3) the relative population size of the amphibian species in terms of tunnel usage and locations.

\section{MATERIALS AND METHODS}

\section{Site visits}

An initial site visit was conducted on 3rd February 2015 with North Lanarkshire Council, University of Glasgow and Froglife all represented, to examine the condition of the site and tunnels (Figs. 1, 2). The tunnels had been installed in 2010 when Loch Road went through its final phase of construction. Amphibian fencing (Herpetosure, Scalford, U.K.) had been installed approximately one year prior to the first visit and was intended to channel the migrating amphibians towards the tunnels and to prevent them crossing the tarmac road. The three amphibian climate tunnels (ACO, Germany) are spaced along $100 \mathrm{~m}$ of road, about $50 \mathrm{~m}$ apart with the fencing on both sides extending between $56 \mathrm{~m}$ and $105 \mathrm{~m}$ beyond the tunnels at either end. Each tunnel has a dome-shaped entrance $30 \mathrm{~cm}$ high and $50 \mathrm{~cm}$ wide, guarded by a metal grid, with fencing arranged to channel animals towards the tunnel entrances. The solid grey, recycled polypropylene, fencing projects about $47 \mathrm{~cm}$ vertically above the ground and has a bevelled top section projecting towards the marsh or loch. Each tunnel is about $13.4 \mathrm{~m}$ long and has a series of $6 \mathrm{~cm} \times 3 \mathrm{~cm}$ ventilation holes running across the road, allowing air, rainwater and light into the tunnels. Tunnel design and lay-out are similar to the European guidelines summarised by Hamer et al. (2015).

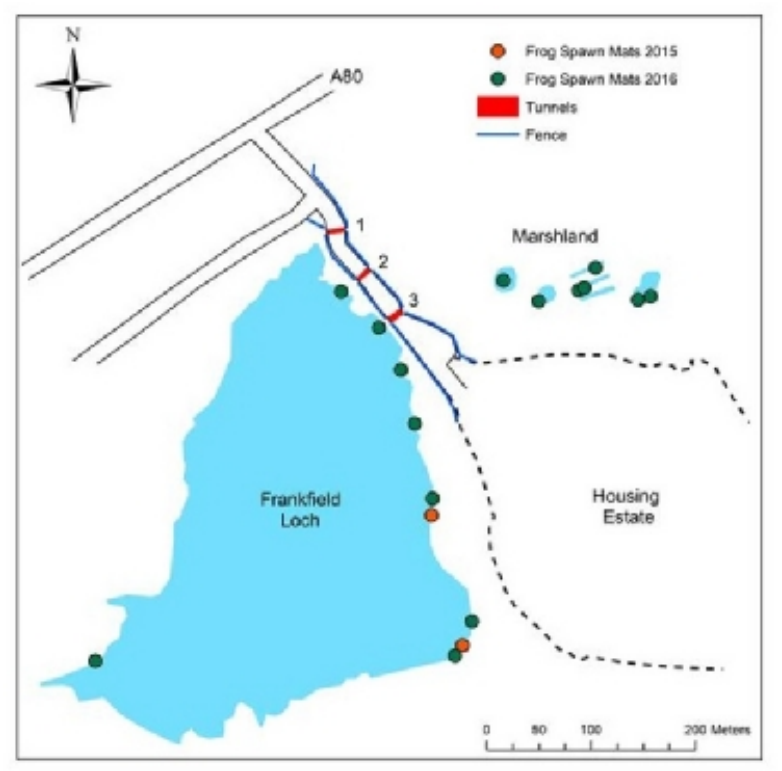

Fig. 1. Frankfield Loch, Stepps, North Lanarkshire and adjacent marshland, showing the positions of the amphibian tunnels (red lines), numbered 1-3. Amphibian fencing is shown as blue lines. Orange dots represent spawn mats identified in 2015 , and green dots represent spawn mats identified in 2016, when a more extensive survey of the area was conducted. 


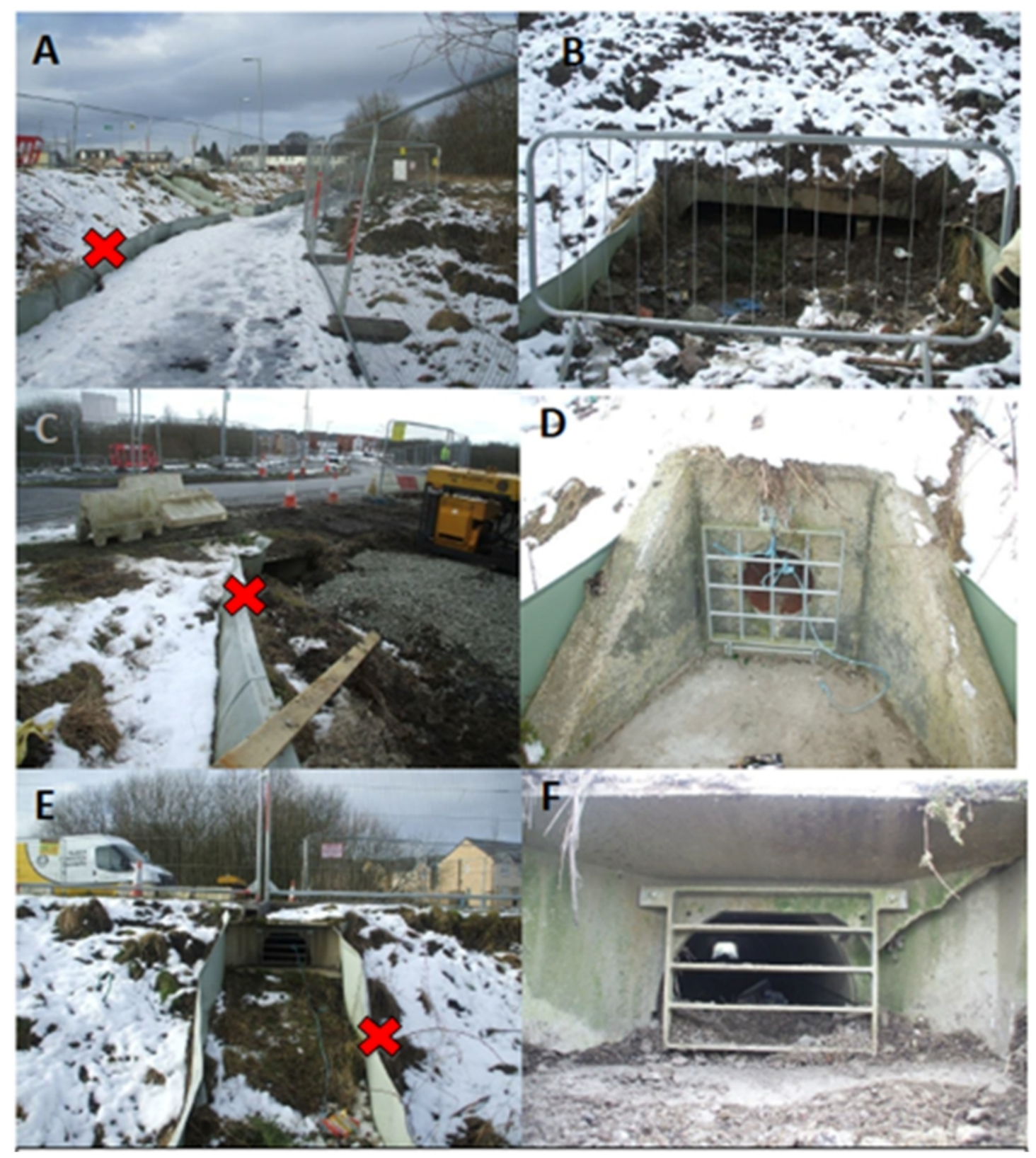

Fig. 2. During a site visit to Frankfield Loch, Stepps, North Lanarkshire on 3rd February 2015 inspection was made of the temporary tarmac footpath (A), the water vole (Arvicola amphibius) tunnel (B), the work being carried out at the loch side entrance to tunnel 1 (C), the water culverts (D) and the frog tunnel entrances on the marsh side of the Loch Road (E and F) which are $30 \mathrm{~cm}$ high and $50 \mathrm{~cm}$ wide. Herpetosure barriers are marked with a red X in (A), (C) and (E). (Photos: I. Hill)

In 2015, road works had recently led to the closing of part of the road and a temporary tarmac path had been laid parallel to Loch Road on the marsh side. This cut across the amphibian fencing, creating a gap to the north at the beginning of Loch Road and to the south, beside tunnel 3 (Fig. 2). The ventilation holes had also been tarmacked over and not reinstated until the summer. Concerns were raised about the site being in this condition during the migration period, but assurances were given that all road works were due to finish by 9th March 2015 as well as the tarmac path removed and amphibian fencing would be put back in place in time for the end of winter hibernation. Despite these intentions, a complication resulted in roadwork completion and fence reinstatement on 2nd April 2015.
There were no road repair issues at the initial site visit in February 2016, but it was noted that burning had damaged a section of the amphibian fencing, and arrangements were made for this to be repaired. On a repeat visit in May 2018, we found that the fencing was in good condition, and that a community group had recently cleared the area of litter.

\section{Camera installation and servicing}

Installation of the camera brackets took place on 18th March 2015. The entrance grids were removed in preparation and frames for the cameras were placed onto a converted carjack that was raised into position approximately one metre from the entrance of the tunnels, at the marshland side. To reduce the chance of theft of the cameras, a blacksmith altered 
the tunnel entrance grids to allow access to the equipment before the grids were further secured into position by filling the boltholes for them with grip adhesive. This meant that the cameras could only be extracted with the use of an extendable pole that had the appropriate thread size to fit the attachment site at the rear of the camera/battery housing. The cameras were installed on 19th March 2015 and data recording began at 10:33 on that day and continued until 9th May 2015. The cameras pointed downwards, using a fish-eye lens to capture images every $10 \mathrm{~s}$ of the tunnel bottom, extending the full width of the tunnel and from the tunnel entrance $1.5 \mathrm{~m}$ back. Illumination was provided by low intensity infrared LEDs attached to the camera mounting. At the end of the first recording period, the cameras were removed and stored away until the next year's data collection, when the cameras were reinstalled and recorded from 8th March 2016 until 30th May 2016. Within both data collection periods, memory cards and batteries were replaced every four days.

A custom-made analysis programme was then run that isolated images that indicated animal movements. The software had been blind-tested by different researchers in a previous project, using a large volume of data, and the results indicated near perfect detection, with less than $0.5 \%$ differences between fully manual and automated analyses (Helldin et al., 2015).

\section{Image analysis}

The images selected post motion-detection analyses were analysed frame by frame (Fig. 3) to identify and record each individual as frog, toad, newt, mammal, invertebrate or other. In the rare instances when an amphibian was only partly visible and therefore indistinguishable between frog and toad, it was recorded as "unknown amphibian". The dorsal field of view did not allow us to identify to species level for small newt females and juveniles (only palmate and smooth newts are known to occur at the site, but their identification requires a clear view of underside markings). The direction of travel was recorded as "West" if the individuals were moving from the marshland to the loch (i.e. from the tunnel entrance to the inside of the tunnel) or, "East" if moving from the loch to the marshland (i.e. from the inside of the tunnel towards the entrance on the marshland side). If the individual turned around under the camera, this would be taken as a U-turn and considered as potential tunnel "rejection". During the analysis, different time periods from the three tunnels were mixed between observers to minimise observer bias.

\section{Human disturbance}

Data collection in 2015 was interrupted by road works and this period has been used to assess what effect human disturbance had on the use of the tunnels. This consisted of three time periods: "path" was the period in which the temporary tarmac path ran along the marsh side of Loch Road (mid-January to 30th March 2015); "work" was the two days (according to the workmen) when the temporary path was being broken up, the earth that had been cleared was placed back over this and the gaps in the amphibian fence were put back in place (31st March 2015 and 1st April 2015); "clear" was the period after this was completed (2nd April 2015 onwards).

\section{Amphibian road mortalities}

In both years, amphibian road deaths were investigated and counted during each visit (every four days, coincident with camera servicing). Only fresh carcasses were recorded in order to avoid double counting.
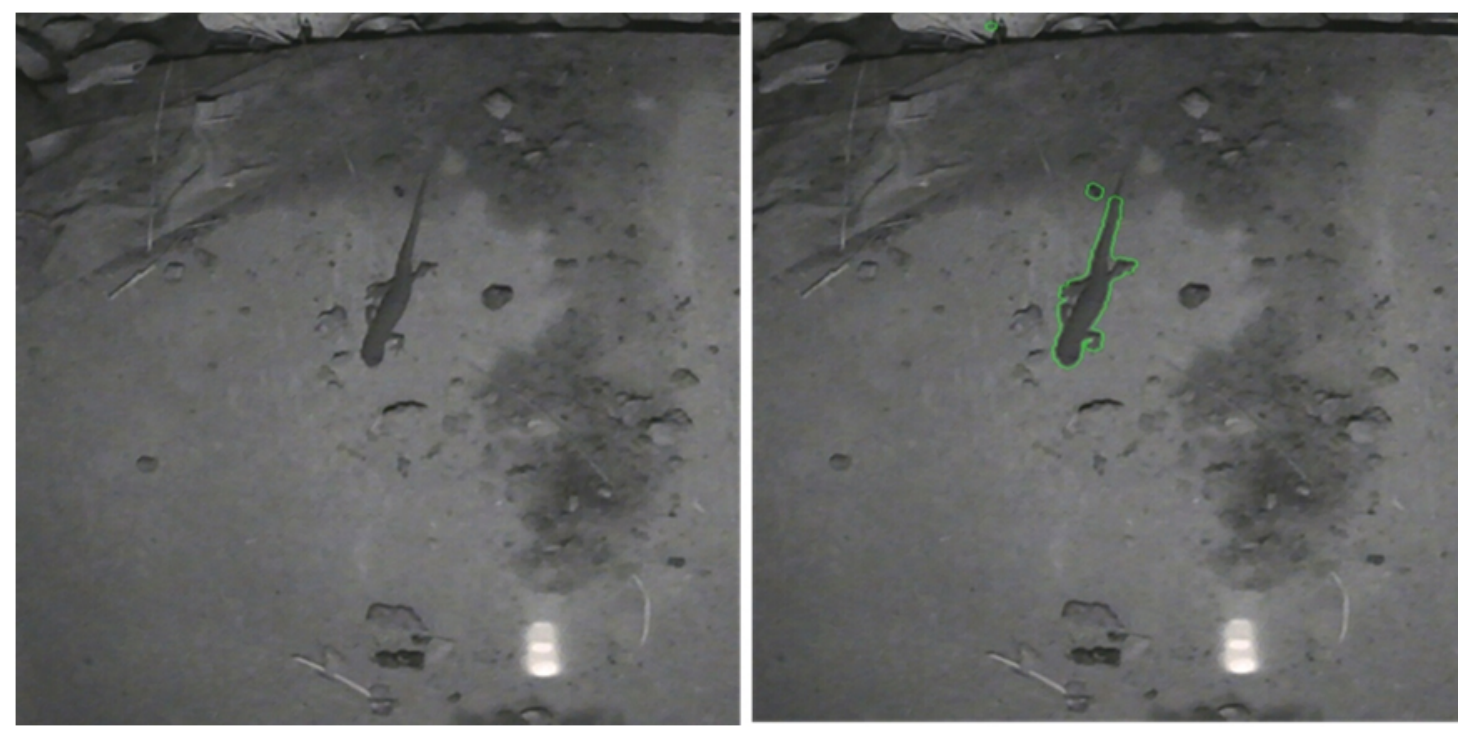

Fig. 3. Image analysis of a newt (Lissotriton spp.) passing through a tunnel at Frankfield Loch, Stepps, North Lanarkshire. When the newt moves the image software analysis outlines in green the contour area where pixel change was detected. (Photos: Froglife) 


\section{Frog spawning locations}

In 2015, four complete circuits around the loch were conducted, searching as far into the reed beds as possible to locate frog spawning sites, on the following dates: 19th, 21st, 25th and 29th March 2015. In 2016, two complete circuits around and loch were conducted locating frog spawn sites. The marshland was also surveyed for frog spawn sites at each pond area (Fig. 1) on 24th March 2016 and 24th April 2016.

\section{Temperature and light periods}

Temperature data for Glasgow, and the sunset/sunrise times during the period of data recording were regularly taken from the website: http://www.timeanddate.com/weather/uk/glasgo $\mathrm{w} /$ historic

\section{Statistical analysis}

General linear models (GLMs) were used to examine the differences in "successful" tunnel usage (movement "West" and "East" through tunnels combined) between years for each species group and total amphibian usage numbers. In addition to the standard packages provided in $\mathrm{R}$ 3.1.1 (http://www.R-project.org/), the ggplot2 R package was also used.

\section{RESULTS}

\section{Species usage}

In both years, newts comprised the majority of amphibian observations (Table 1) and frogs and newts had the widest range of dates recorded (Fig. 4 ), whereas toad activity had a narrower range of dates, indicating a more restricted migration period. "East" movements, particularly in 2015, were greater for frogs and toads than newts (Table 1). Additionally, a greater number of frogs were moving "East" rather than "West" during 2015. Overall, "West" movements (from the marshland towards the loch) were greater than "East" movements in both years. Though "successful" tunnel uses by frogs and newts increased marginally, "successful" uses by toads decreased significantly from 2015 to 2016 (Toad $t_{1}=-4.207, \mathrm{p}=<0.0001$ ) (Fig. 5).

The proportions of immediately visible tunnel "rejections" were fairly consistent (8-9\% of all amphibian observations) over the two years, though rejections by frogs were less frequent than by toads or newts in both years (Table 1 ).

Initial migration date cannot be determined from current data, as some activity was recorded on the first recording day during each year. However, numbers recorded in 2015 were very low until day 87 (28th March) and a similar increase in 2016 occurred 15 days earlier. There was some movement throughout the recording period, but numbers declined sharply after day 115 (25th April ) in 2015 and day 105 (15th April) in 2016. Toad movements tended to cluster over a fairly narrow time period (days 87-105 in 2015; 82-104 in 2016), whereas movements of newts and frogs extended over a wider period.

Though not included in analysis, instances of invertebrates, small mammals and birds were also recorded.

\section{Tunnel usage and human disturbance}

The patterns of tunnel use were strikingly different over the two years (Table 2; Fig. 6). In 2015, well over half of the "successful" uses occurred through tunnel 3, furthest from the roadworks. In 2016, tunnel use was much more even, with tunnel 2 recording the largest number of uses. Fig. 6 shows that, if we can consider 2016 as the "normal" pattern unaffected by roadworks, there were several migration "peaks" over an extended period, whereas in 2015 , there was a single higher peak after the roadworks were completed. In the disturbed period, use of tunnel 1 was particularly low compared with 2016.

\begin{tabular}{|c|c|c|c|c|c|c|}
\hline \multirow{2}{*}{$\frac{\text { Year }}{\text { Species }}$} & \multicolumn{3}{|l|}{2015} & \multicolumn{3}{|l|}{2016} \\
\hline & West & East & $\begin{array}{l}\text { Rejection } \\
(\%)\end{array}$ & West & East & $\begin{array}{l}\text { Rejection } \\
(\%)\end{array}$ \\
\hline Toads & 371 & 311 & $\begin{array}{l}77 \\
(10.1)\end{array}$ & 219 & 176 & $\begin{array}{l}33 \\
(7.7)\end{array}$ \\
\hline Frogs & 80 & 206 & $\begin{array}{l}16 \\
(5.3)\end{array}$ & 171 & 190 & $\begin{array}{l}15 \\
(4.0)\end{array}$ \\
\hline Newts & 730 & 378 & $\begin{array}{l}101 \\
(8.4)\end{array}$ & 756 & 583 & $\begin{array}{l}176 \\
(11.6)\end{array}$ \\
\hline Total & 1181 & 895 & 194 & 1146 & 949 & 224 \\
\hline
\end{tabular}

Table 1. Total numbers of amphibians recorded using the tunnels, moving "West" towards the loch and "East" towards the marsh, or turning within the tunnels ("rejection"), at Frankfield Loch, Stepps, North Lanarkshire in 2015 and 2016. Toads (Rana temporaria), frogs (Bufo bufo), and "newts" includes palmate newt (Lissotriton helveticus) and smooth newt (L. vulgaris). 
A

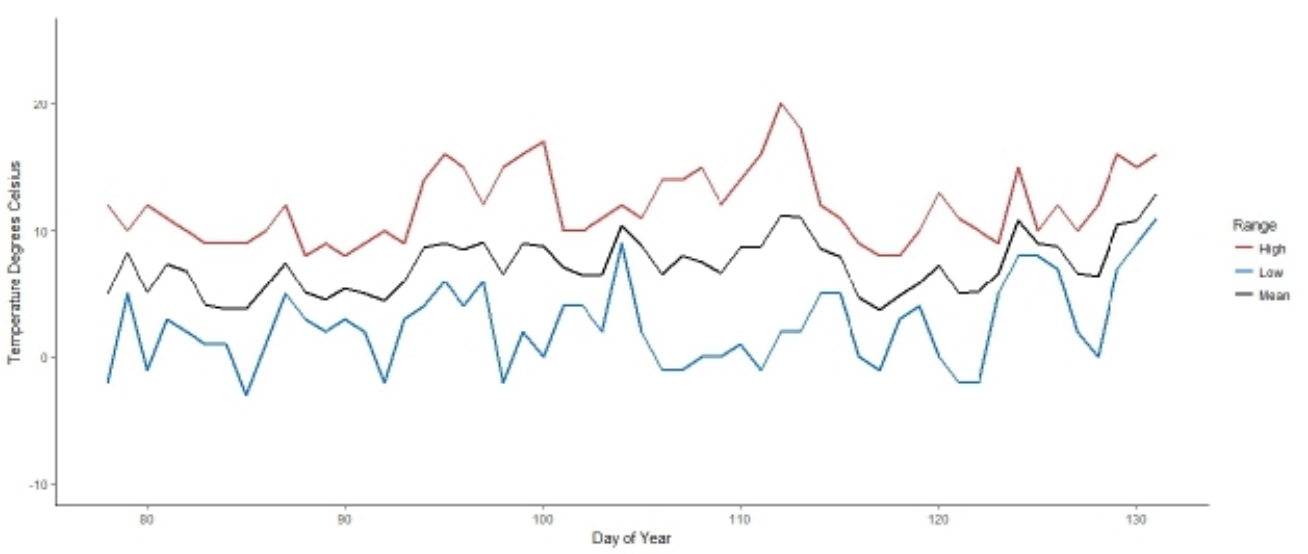

B



C

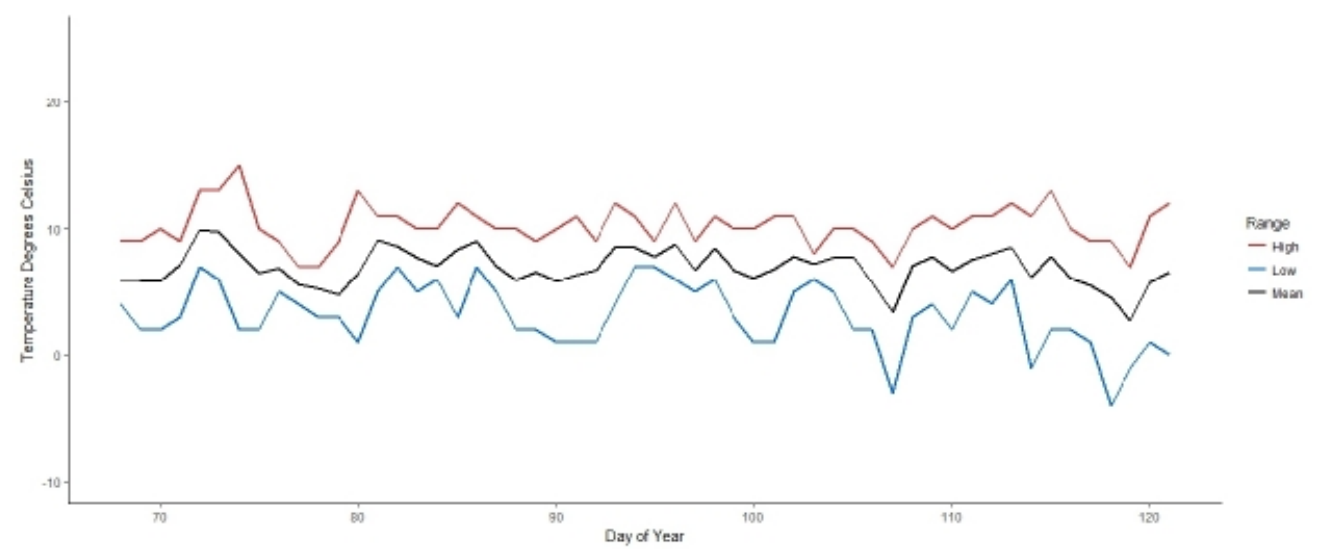

D

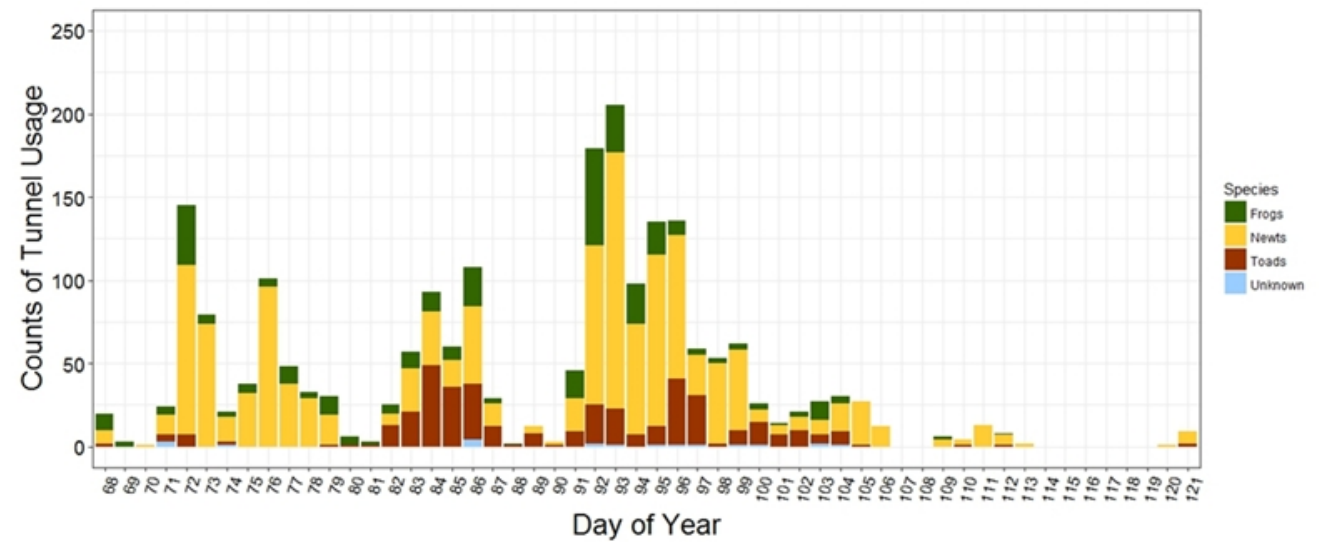

Fig. 4. Line plot of high, low and mean temperatures of the area of Frankfield Loch, Stepps, North Lanarkshire for 2015 (A) and 2016 (C). Successful tunnel uses ("West" and "East" uses summed) recorded for 2015 (B) and 2016 (D). Day of the year is given as a count from 1st January. Frogs (Rana temporaria), toads (Bufo bufo) and "newts" includes both palmate newt (Lissotriton helveticus and smooth newt (L. vulgaris). "Unknown" includes indistinguishable frogs and toads. Periods of roadworks during 2015 shown as "Path", "Work" and "Clear". 


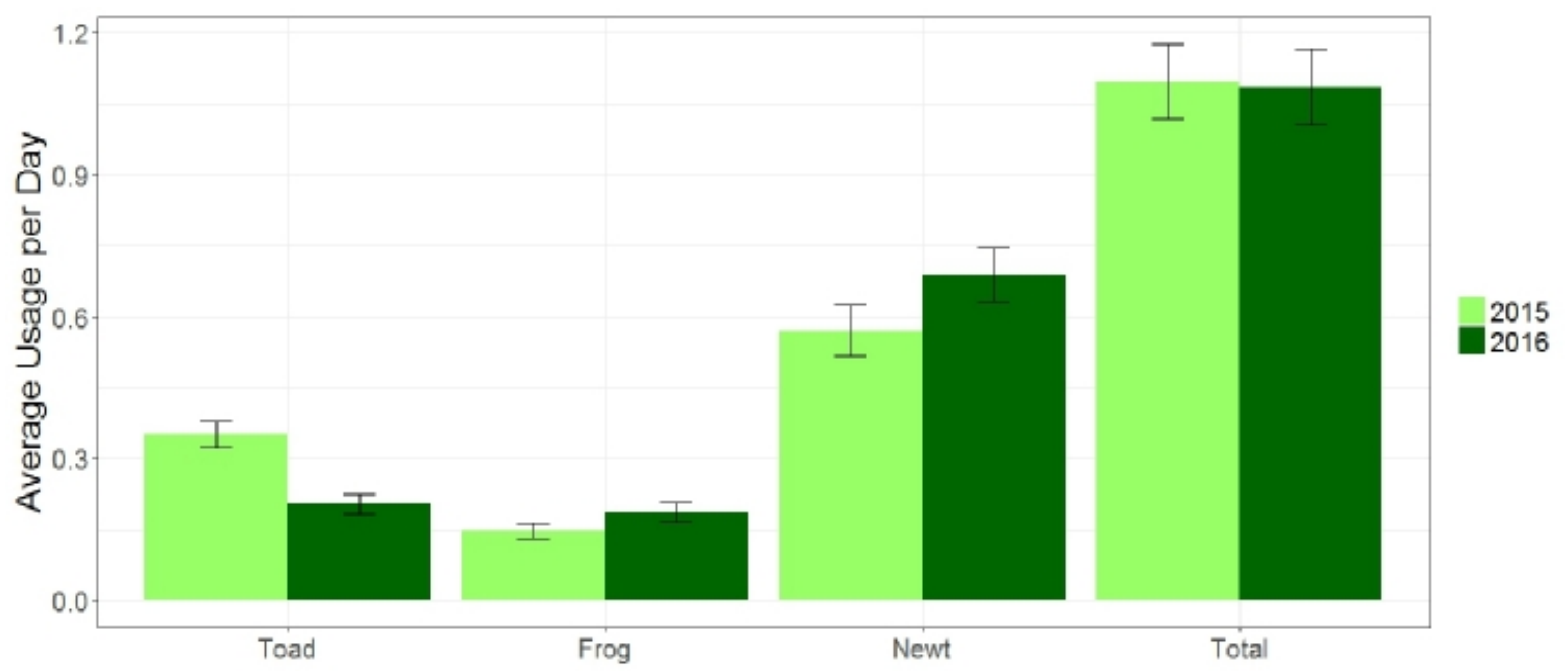

Fig. 5. Average (+/- SE) tunnel usage per day ("West" and "East" uses summed) by amphibians at Frankfield Loch, Stepps, North Lanarkshire from 2015 and 2016.

A

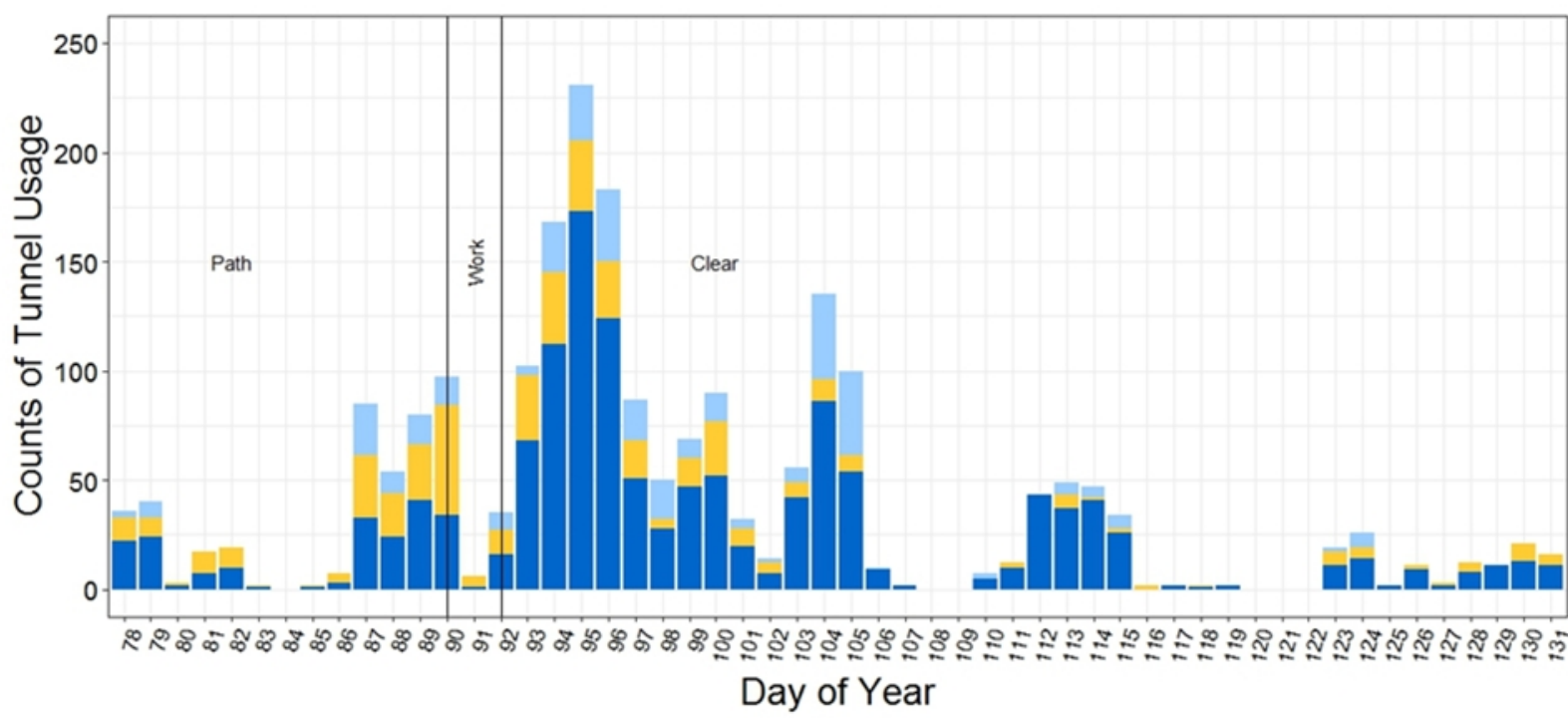

B

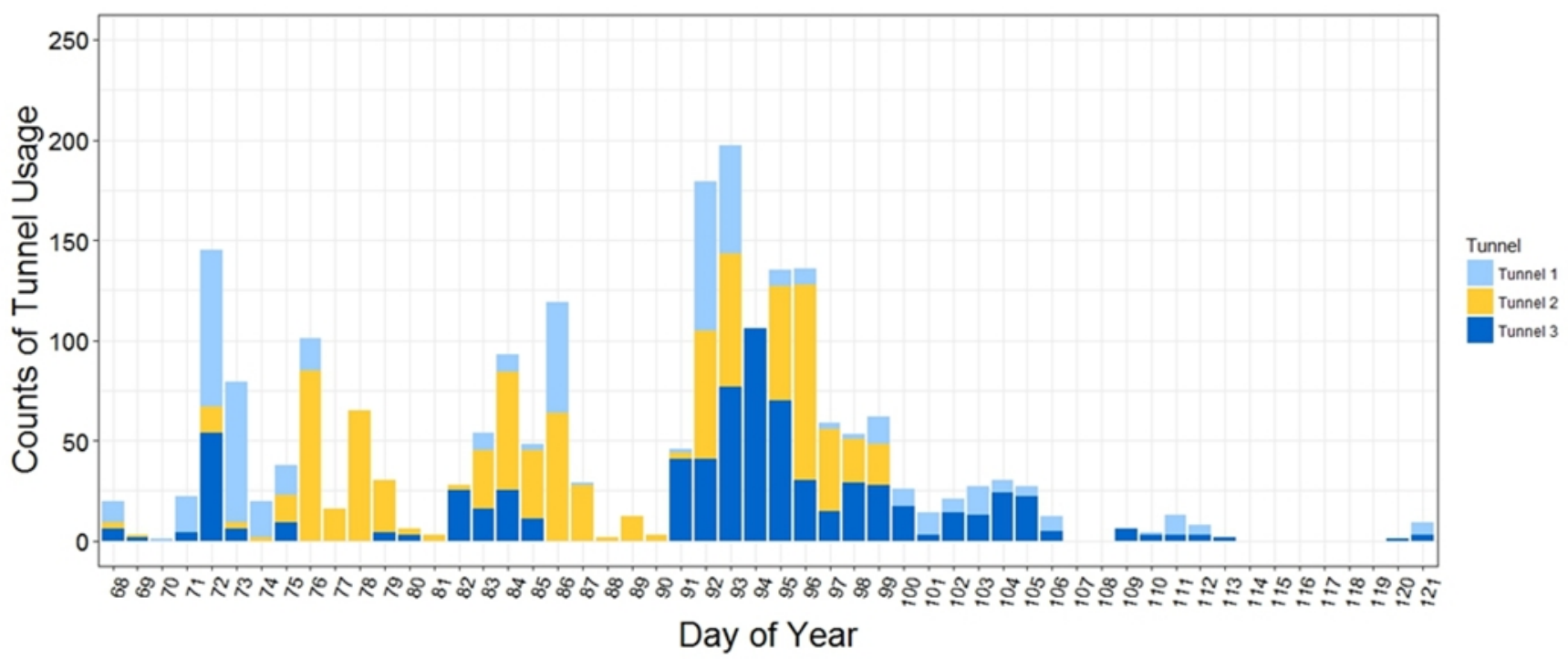

Fig. 6. Successful tunnel usage ("West" and "East" uses summed) by amphibians at Frankfield Loch, Stepps, North Lanarkshire recorded for 2015 (A) and 2016 (B). Legend details same as in Fig. 5. 


\begin{tabular}{lllll}
\hline Tunnel & $\mathbf{2 0 1 5}$ & $\mathbf{\%}$ & $\mathbf{2 0 1 6}$ & $\mathbf{\%}$ \\
\hline $\mathbf{1}$ & 344 & 16.13 & 550 & 26.07 \\
$\mathbf{2}$ & 447 & 20.96 & 839 & 39.76 \\
$\mathbf{3}$ & 1342 & 62.92 & 721 & 34.17 \\
Total & 2133 & 100 & 2110 & 100 \\
\hline
\end{tabular}

Table 2. Total successful amphibian uses of tunnels by tunnel ("West" and "East"), year (2015 and 2016) and percentage at Frankfield Loch, Stepps, North Lanarkshire.

\section{Amphibian road mortalities}

The high level of frog road deaths recorded in 2015 (Table 3) was associated with the gap in the amphibian fencing during the "path" period and a high number of frog movements around day 88 (Figs. $4,6)$. The high incidence of newt deaths over days 96-101 corresponds with a peak in their movement and a gap in the amphibian fencing identified during the initial "clear" period, indicated by high numbers of road mortalities near the gap beside tunnel 3 . Although monitoring for road mortality also occurred in 2016, no road deaths were observed.

\begin{tabular}{llll}
\hline Date & Toads & Frogs & Newts \\
\hline 21/03: day 80 & 0 & 2 & 0 \\
29/03: day 88 & 0 & 18 & 0 \\
02/04: day 92 & 0 & 2 & 0 \\
06/04: day 96 & 0 & 4 & 57 \\
11/04: day 101 & 1 & 4 & 26 \\
15/04: day 105 & 0 & 2 & 0 \\
24/04: day 114 & 0 & 0 & 1 \\
28/04: day 118 & 0 & 0 & 1 \\
06/05: day 126 & 0 & 0 & 1 \\
Total & 1 & 32 & 86 \\
\hline
\end{tabular}

Table 3. Dates and counts of observed amphibian road deaths at Frankfield Loch, Stepps, North Lanarkshire in 2015. Toads (Rana temporaria), frogs (Bufo bufo), and "newts" includes palmate newt (Lissotriton helveticus) and smooth newt (L. vulgaris).

\section{Frog spawning locations}

Common frog breeding sites around the loch were observed in 2015 through the presence of spawn mats. A more thorough investigation carried out in 2016 identified a number of breeding site locations within the marsh (including ponds installed as part of mitigation procedures during housing development) and around the circumference of the loch (Fig. 1).
Temperature and light periods: relationships with tunnel interactions

Mean temperatures between the two years were similar in their range with no consistent rise, though fluctuations were greater in 2015 (Fig. 4A,C). Amphibian activity was highest at night and lowest during daylight hours for all species. A further preference for sunset periods rather than sunrise was indicated for all species in both years (Fig. 7; Table 4).

\section{DISCUSSION}

Hamer et al. (2015) noted that amphibians are often the vertebrate group most at risk from road mortalities, and that the challenge of any amphibian mitigation measure is "to prevent road-kills and to maintain habitat connectivity". These tunnel monitoring results at Frankfield demonstrate that there is substantial two-way movement of all four local amphibian species between the marsh and the loch areas. The common frog breeding data show that spawning occurs both in the marsh ponds and in the reedy shallows around the loch edge. We have no data on toad or newt spawning, but it is likely that it occurs on both sides of the road, given the suitability of the habitat. Clearly, the loch and the marsh constitute a connected amphibian habitat and the tunnels are allowing animals to move from one side to the other.

We found amphibian road-kills only in 2015, coinciding with the period of disruption to the fencing caused by the roadworks. Hamer et al. (2015) noted that road construction "should be timed to avoid periods of high amphibian activity" and that regular inspection and maintenance of both fencing and tunnels are essential aspects of successful road mitigation. Unfortunately, the 2015 roadworks violated these requirements, with the road repair work extending into the migration season. There was no such problem in 2016, but an early season inspection showed that a section of the fence had been damaged, presumably by vandalism; this was repaired in time for the breeding season, and no further road-kills were observed. The roadkill data are likely to be underestimates, given the speed with which scavengers can locate and feed on or remove carcasses (Santos et al., 2011). However, the difference between the 2015 and 2016 data indicates an effect of the road repairs. We hope that the need for regular inspection and maintenance has been fully recognised.

The use of automatic tunnel-sited cameras allowed us to assemble a much more comprehensive picture of amphibian movements than is possible with other methods and with a modest expenditure of fieldwork time (this equipment carries a comparable cost to modern trail cameras, but please contact Froglife for further details). 
A

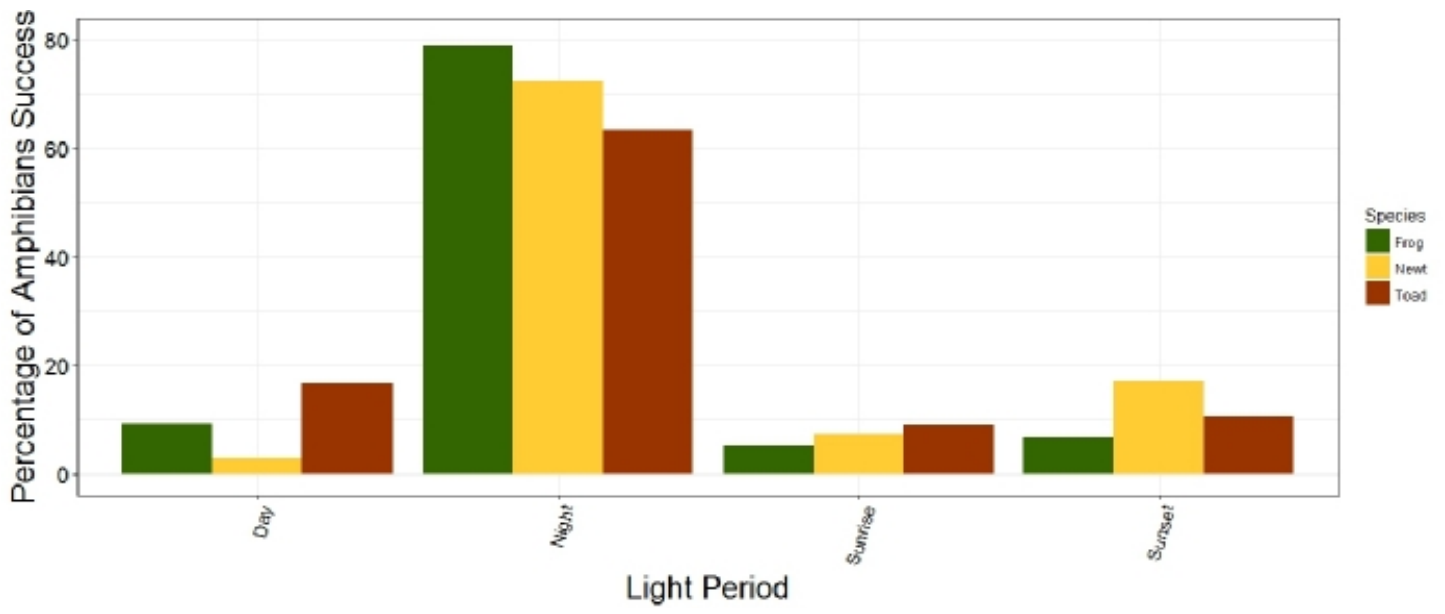

B

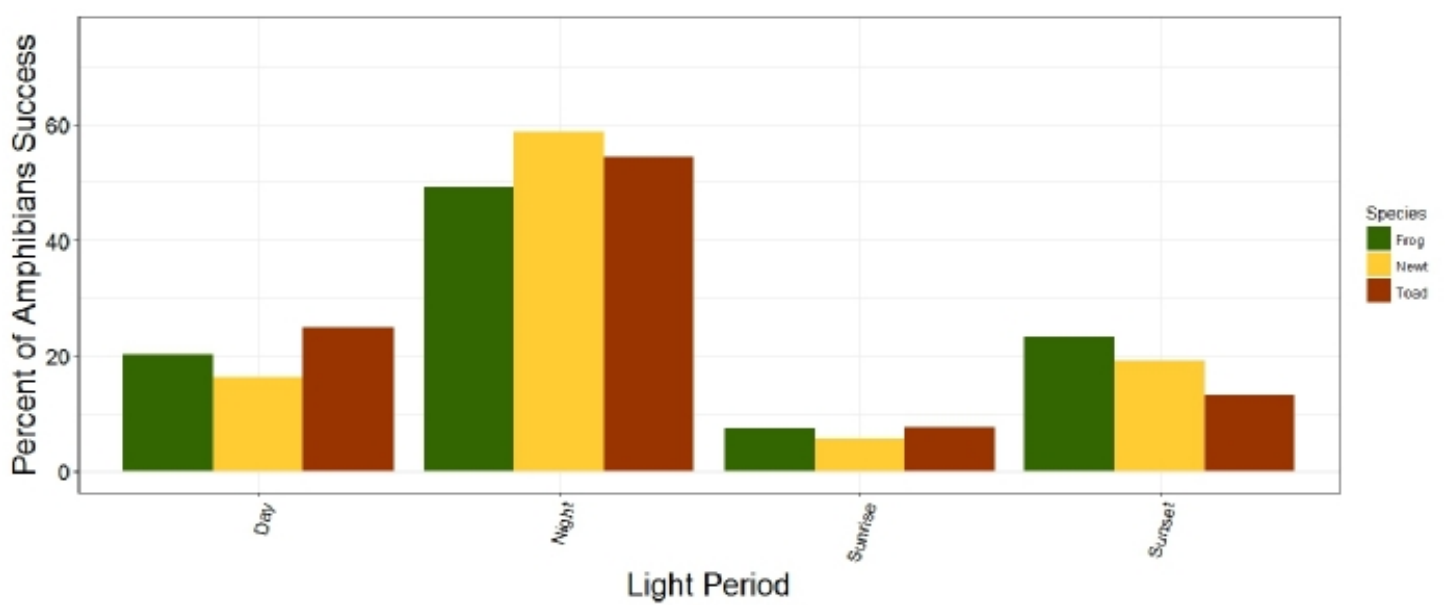

Fig. 7. Percentage of successful uses ("West" and "East" uses summed) by amphibians at Frankfield Loch, Stepps, North Lanarkshire by light period (sunrise and sunset representing the two-hour period around these times), for 2015 (A) and 2016 (B). Frog (Rana temporaria), toad (Bufo bufo), and "newt" includes both palmate newt (Lissotriton helveticus and smooth newt (L. vulgaris).

\begin{tabular}{lllllllll} 
& Toads & & Frogs & & Newts & \multicolumn{3}{c}{ Total } \\
\cline { 2 - 9 } & $\mathbf{2 0 1 5}$ & $\mathbf{2 0 1 6}$ & $\mathbf{2 0 1 5}$ & $\mathbf{2 0 1 6}$ & $\mathbf{2 0 1 5}$ & $\mathbf{2 0 1 6}$ & $\mathbf{2 0 1 5}$ & $\mathbf{2 0 1 6}$ \\
\hline Sunrise & 9.09 & 7.59 & 5.26 & 7.48 & 7.31 & 5.68 & 7.61 & 6.35 \\
Day & 16.86 & 24.81 & 9.12 & 20.22 & 2.98 & 16.28 & 8.39 & 18.57 \\
Sunset & 10.71 & 13.16 & 6.67 & 23.27 & 17.24 & 19.19 & 13.64 & 18.76 \\
Night & 63.34 & 54.43 & 78.95 & 49.03 & 72.47 & 58.85 & 70.36 & 56.32 \\
\hline
\end{tabular}

Table 4. Percentages of total successful tunnel use ("West" and "East") by amphibian species, year and light period, at Frankfield Loch, Stepps, North Lanarkshire in 2015 and 2016. Toads (Rana temporaria), frogs (Bufo bufo), and "newts" includes palmate newt (Lissotriton helveticus) and smooth newt (L.vulgaris).

Matos et al. (2017) reported on five years of data from road tunnels on Hampton Nature Reserve. Great crested newt numbers entering and leaving the tunnels were assessed from animals caught in pitfall traps. This study provided valuable data, but the method is labour intensive and therefore costly, typically resulting in a highly restricted period of monitoring. Additionally, catching amphibians in pitfall traps biases the data by introducing a significant disturbance factor (i.e. animals trapped at the tunnel entrance cannot complete the crossing until released, but also, since movements are often bi-directional, trapping on one side only potentially underestimates the number of movements). Pagnucco et al. (2011) monitored salamander movements into tunnels using motion-triggered cameras, timed-interval images and pitfall traps as a control. Although they concluded that the cameras were effective, their data indicate that over $40 \%$ of 
the animals failed to trigger the motion detectors due to small size and slow movements.

In this study, frog and newt movements extended throughout the monitoring period in both years from March to May, but with movement numbers low in May. Movements of toads tended to be more tightly clustered around a peak from late March to midApril. Significant frog and newt movements began later in 2015 than in 2016, most likely related to the cold weather persisting into March.

Although all species showed large numbers of "successful" tunnel uses (assuming that smooth and palmate newts, which we could not distinguish, behaved similarly), there were fairly consistent species differences across the two years in the proportion of individuals which turned around and exited a tunnel after entering it. Such tunnel rejections occurred more commonly among newts and toads than among frogs. We do not have a good explanation for these differences, but they might be related to how microclimate variations within the tunnels are perceived by different amphibian species. Although animals other than amphibians used the tunnels, including occasional instances when we detected opportunistic amphibian predators such as brown rats, hedgehogs and domestic cats, if predator-avoidance was a cause of tunnel rejection, we would expect toads, with their good anti-predator defences, to show the lowest level of rejection. In an experimental set-up, Hamer et al. (2014) found that several species of Australian frogs were reluctant to enter tunnels, but they noted that such aversion had not been detected in European studies.

The pattern of tunnel usage differed markedly between the two years, with tunnel 3 the most heavily used in 2015, while usage was more evenly spread in 2016. The most obvious explanation for this difference is the disturbance related to the 2015 roadworks, located closest to tunnel 1 and furthest from tunnel 3.

The continuous automatic monitoring allowed an assessment of the diurnal patterns of amphibian movements. Although night-time was the most common movement period for all species, daytime and sunset periods were not negligible, and the lowest numbers of movements were at sunrise for all species.

These results do not allow us to measure amphibian populations at the site. We have no data on how many individuals hibernate and breed on the same side of the road, without having to move thorough the tunnels. In addition, we do not know whether each tunnel use was by a separate individual, or whether some or all individuals used the tunnels more than once. It is likely that the early movements up to the peaks in late March represent individuals moving to a breeding location, with little reason to return immediately. Later, however, movements are likely to represent dispersals to foraging sites after breeding, and therefore represent individuals recorded moving in the opposite direction to their earlier movement. Numbers were fairly consistent over the two years, except that toads showed a significant decline in 2016. More data are needed to determine whether this finding reflects the overall decline in U.K. toad populations reported by Petrovan \& Schmidt (2016) or simply annual variation, which can be high in this species.

One caveat is needed when considering these results. We imply that each amphibian detected is migrating through the tunnel to the other side, unless it turns around within the camera's field of view (an area of about $0.5 \mathrm{~m} \times 0.5 \mathrm{~m}$ extending $1.5 \mathrm{~m}$ from the tunnel entrance within a $13 \mathrm{~m}$ long tunnel), which we class as a tunnel rejection. This method cannot make this certain and it is likely that more amphibians make a U-turn at other points within the tunnels. Verification would require cameras to be installed at both ends and the images of amphibians at the start and end correlated, a difficult and laborious task. However, where this technique was used at two sites over three years, using the same camera equipment, the majority of amphibians, especially newts, spent little time in the tunnels, normally using them only for crossing, although male toads might spend more hours in tunnels as refuge, sometimes spending daytimes there and moving out during the subsequent night (Petrovan, unpublished data). We believe that the assumption that most amphibians entering the tunnels continue through to the other side is justified for the following reasons. Early spring migrations are about breeding, and most of the species we have monitored tend to breed in their natal ponds. They locate these ponds using a combination of physical and chemical cues (Sinsch, 1991; Joly \& Miaud, 1993). A narrow tunnel may seem artificial to us, but is likely to provide a rich linear source of breeding-pond data, such as volatile chemicals, to a small amphibian.

At $13 \mathrm{~m}$ long, the Frankfield tunnels are shorter than many other tunnels installed in the U.K., which are typically $20 \mathrm{~m}$ long, but can be as much as 30-40 m (Matos et al., 2017; White et al., 2017). Shorter tunnels are likely to have significantly lower rejection rates compared to longer tunnels. In addition, the climate tunnels used at Frankfield have ventilation holes at the top, flush with the road surface, and these greatly facilitate air exchange and minimise differences in temperature and humidity between the tunnels and the external environment. However, ventilation holes allow road pollutants, including heavy metals and salt to enter the tunnels, especially during rainfall, and these can have detrimental effects on amphibians using the tunnels (White et al., 2017). A simple solution would be to flush the tunnels with water each spring before the 
main amphibian migration, as is commonly done in other European countries. This would also allow the removal of accumulated dead leaves and litter, which can act as barriers to amphibian migration. Although the tunnel entrance grids at Frankfield prevent the entry of larger items of litter, images did show many smaller litter items such as cigarette packet wrappers.

This case study of amphibian mitigation tunnels at Frankfield Loch has demonstrated the efficacy of non-invasive amphibian monitoring using custombuilt cameras located in the tunnels. The results show that the tunnels are well used by the local species of amphibians and that the combination of tunnels and amphibian-proof fencing can prevent road mortalities when the system is intact and well maintained. Reference to the literature on road mitigation indicates some desirable management practices such as tunnel flushing to remove pollutants. In detail, the results show interesting interannual and interspecific differences. To build a picture of amphibian dynamics at the site, further research is needed, including more breeding data of the sort reported here from a two-year period.

\section{ACKNOWLEDGEMENTS}

In 2016, this work was generously supported by a research internship grant to IH from the People's Trust for Endangered Species. In 2015 the work was supported by an award from Taylor Wimpey. Both IH and CR received support from IBAHCM, University of Glasgow. At Froglife, SP was supported by a research grants from the British Ecological Society, the People's Trust for Endangered Species and a grant from Esmé Fairbairn Foundation. Gilles Dubois, Ben Killick, Marine Seidel helped with image analysis. Tiffany Armstrong helped with data collection and analysis. Liam Templeton, Jake Easto and Emily Waddell assisted in the field. Robert McGinney, Taylor Wimpey site manager, facilitated site access and ecologist Adam Fitchett introduced the site to us. Pardeep Chand and Laura McCrorie, North Lanarkshire Council, helped set up the project.

\section{REFERENCES}

Al-ghamdi, A.S. \& Algadhi, S.A. (2004). Warning signs as countermeasures to camel-vehicle collisions in Saudi Arabia. Accident Analysis \& Prevention 36, 749-760.

Beebee, T.J.C. (2013). Effects of road mortality and mitigation measures on amphibian populations. Conservation Biology 27, 657-668.

Cushman, S.A. (2006). Effects of habitat loss and fragmentation on amphibians: A review and prospectus. Biological Conservation 128, 231240.

Foley, J.A., Defries, R., Asner, G.P., Barford, C., Bonan, G., Carpenter, S.R. et al. (2005). Global consequences of land use. Science 309, 570-574.
Frid, A. \& Dill, L. (2002). Human-caused disturbance stimuli as a form of predation risk. Ecology and Society 6, 11.

Gryz, J. \& Krauze, D. (2008). Mortality of vertebrates on a road crossing the Biebrza Valley (NE Poland). European Journal of Wildlife Research 54, 709-714.

Hamer, A.J., Van der Ree, R., Mahony, M.J. \& Langton, T. (2014). Usage rates of an under-road tunnel by three Australian frog species: Implications for road mitigation. Animal Conservation 17, 379387.

Helldin, J.O., Koffman, A., Söderström-Lööf, C., Jondelius, E., Hartup, M. \& Petrovan, S.O. (2015). Groddjurstunnlar Spångavägen Rapport 201510-02 Calluna Consultancy

http://miljobarometern.stockholm.se/content/d ocs/tema/natur/Groddjur/Groddjurstunnlar\%2 0Sp\%C3\%A5ngav\%C3\%A4gen\%20Rapport\%20 2015-10-02.pdf

IUCN 2015. The IUCN Red List of Threatened Species. Version 2015-3.

Jaeger, J.A.G. \& Fahrig, L. (2004). Effects of road fencing on population persistence. Conservation Biology 18, 1651-1657.

Joly, P. \& Miaud, C. (1993). How does a newt find its pond? The role of chemical cues in migrating newts (Triturus alpestris). Ethology Ecology \& Evolution 5, 447-455.

Kiesecker, J.M., Blaustein, A.R. \& Belden, L.K. (2001). Complex causes of amphibian population declines. Nature 410, 681-684.

Matos, C., Petrovan, S., Ward, A.I. \& Wheeler, P. (2017). Facilitating permeability of landscapes impacted by roads for protected amphibians: patterns of movement for the great crested newt. PEERJ 5, e2922. https://doi.org/10.7717/peerj.2922

Nyström, P., Hansson, J., Månsson, J., Sundstedt, M., Reslow, C. \& Broström, A. (2007). A documented amphibian decline over 40 years: Possible causes and implications for species recovery. Biological Conservation 138, 399-411.

Pagnucco, K.S., Paszkowski, C.A. \& Scrimgeour, G.J. (2011). Using cameras to monitor tunnel use by long-toed salamanders (Ambystoma macrodactylum): An informative, cost-efficient technique. Herpetological Conservation and Biology 6, 277-286.

Petrovan, S.O. \& Schmidt, B.R. (2016). Volunteer conservation action data reveals large-scale and long-term negative population trends of a widespread amphibian, the common toad (Bufo bufo). PLoS ONE 11, e0161943. https://journals.plos.org/plosone/article?id=10. 1371/journal.pone.0161943

Petranka, J.W., Harp, E.M., Holbrook, C.T. \& Hamel, J.A. (2007). Long-term persistence of amphibian populations in a restored wetland complex. Biological Conservation 138, 371-380.

Pounds, J.A., Bustamante, M.R., Coloma, L.A., Consuegra, J.A., Fogden, M.P.L., Foster, P.N. et al. 
(2006). Widespread amphibian extinctions from epidemic disease driven by global warming. Nature 439, 161-167.

$\mathrm{R}$ Core Team (2017). R: A Language and Environment for Statistical Computing. R Foundation for Statistical computing, Vienna, Austria. http://www.R-project.org/

Richter, S.C., Young, J.E., Seigel, R.A. \& Johnson, G.N. (2001). Postbreeding movements of the dark gopher frog, Rana sevosa Goin \& Netting: implications for conservation and management. Journal of Herpetology 35, 316-321.

Roos, S., Johnston, A. \& Noble, D. (2012). UK Hedgehog datasets and their potential for longterm monitoring. BTO Research Report 598, 1-63.

Santos, S.M., Carvalho, F. \& Mira, A. (2011). How long do the dead survive on the road? Carcass persistence probability and implications for road-kill monitoring surveys. PLoS ONE 6, e25383.

https://doi.org/10.1371/journal.pone.0025383

Santos, X., Llorente, G. A., Montori, A., Carretero, M.A., Franch, M., Garriga, N. et al. (2007) Evaluating factors affecting amphibian mortality on roads: The case of the common toad Bufo bufo, near a breeding place. Animal Biodiversity and Conservation 30, 97-104.

Sawaya, M.A., Kalinowski, S.T. \& Clevenger, A.P. (2014). Genetic connectivity for two bear species at wildlife crossing structures in Banff National Park. Proceedings of the Royal Society B Biological Sciences 281, 20131705.

Sinsch, U. (1991). Mini review: the orientation behaviour of amphibians. Herpetological Journal 1, 541-544.

Smith, R.K., Meredith, H. \& Sutherland, W.J. (2018). Amphibian conservation. In: Sutherland, W.J., Dicks, L.V., Ockendon, N., Petrovan, S.O. \& Smith, R.K. (Editors). What Works in Conservation 2018, pp. 9-65. Open Book Publishers, Cambridge, UK.

U.K. Government (2016). Road lengths in Great Britain: 2015.

https://www.gov.uk/government/statistics/roa d-lengths-in-great-britain-2015

Van der Ree, R., Smith. J.D. \& Grilo, C. (2015). Handbook of Road Ecology. Wiley Blackwell, Hoboken, New Jersey, U.S.A.

White, K.J., Mayes, W.M. \& Petrovan, S.O. (2017). Identifying pathways of exposure to highway pollutants in great crested newt (Triturus cristatus) road mitigation tunnels. Water and Environment Journal 31, 310-316.

Wickham, H. (2009). ggplot2: elegant graphics for data analysis. Springer-Verlag New York. 